\title{
Prevalence of Diabetes Mellitus and its associated risk factors
}

\section{Mahendra Singh $^{1}$, Surekha Kishore ${ }^{2}$, Bhavna Jain ${ }^{3}$, Sanjeev Kishore ${ }^{4}$, Pradeep Aggarwal ${ }^{5}$, Shikhar K. Verma ${ }^{6}$}

${ }^{1}$ Assistant Professor, Department of Community and Family Medicine, All India Institute of Medical Sciences Rishikesh; ${ }^{2}$ Professor and Head, Department of Community and Family Medicine, All India Institute of Medical Sciences Rishikesh; ${ }^{3}$ Senior Resident, Department of Community and Family Medicine, All India Institute of Medical Sciences Rishikesh; ${ }^{4}$ Professor and Head of Department, Department of Pathology, All India Institute of Medical Sciences Rishikesh; ${ }^{5}$ Associate professor,

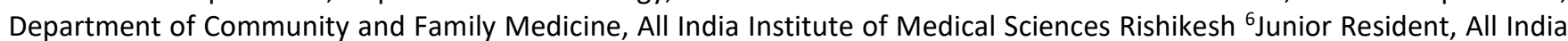
Institute of Medical Sciences Rishikesh

\begin{tabular}{|c|c|c|c|c|c|c|c|c|}
\hline Abstract & Introduction & Methodology & Results & Conclusion & References & Citation & \multicolumn{2}{|c|}{ Tables / Figures } \\
\hline \multicolumn{9}{|c|}{ Corresponding Author } \\
\hline \multicolumn{8}{|c|}{$\begin{array}{l}\text { Dr Bhavna Jain, Senior Resident, Department of Community and Family Medicine, All India Institute of } \\
\text { Medical Sciences Rishikesh, Uttarakhand } \\
\text { E Mail ID: } \underline{\text { drbhavnajain@yahoo.co.in }}\end{array}$} & 回评国 \\
\hline
\end{tabular}

\section{Citation}

Singh M, Kishore S, Jain B, Kishore S, Aggarwal P, Verma SK. Prevalence of Diabetes Mellitus and its associated risk factors. Indian J Comm Health. 2020;32(1):97-100.

Source of Funding: Nil Conflict of Interest: None declared

\section{Article Cycle}

Received: 22/11/2019; Revision: 08/01/2020; Accepted: 15/02/2020; Published: 31/03/2020

This work is licensed under a Creative Commons Attribution 4.0 International License.

\section{Abstract}

Background: Type 2 diabetes mellitus (T2DM) is a chronic, debilitating non communicable diseases (NCDs) which has emerged as a leading global health problem. Aim \& Objective: To find out the prevalence of known cases of diabetes mellitus and associated risk factors in the study area. Material \& Methods: Community-based cross-sectional study was conducted among people living in Barrage colony of Rishikesh, Uttarakhand for a period of 3 months from December 2018 to February 2019. House to house survey was done in all the four blocks (A, B, C, D) of Barrage colony. Total of 815 study participants (both male and female) $\geq 20$ years of age were surveyed. Data collected was entered into Microsoft Excel and analyzed using epi info software version 7. Results: The prevalence of DM was found to be high i.e $5.6 \%$ among the study participants. Prevalence was significantly more among females as compared to males and significantly increased by aging in both genders. Conclusions: It seems that the prevalence of diabetes is increasing in our region as well as our country and the world. To control DM public health education regarding consumption of balanced diet, increasing physical activity and leading a stressfree life is needed.

\section{Keywords}

Diabetes Mellitus; Prevalence; Risk Factors

\section{Introduction}

Diabetes mellitus (DM) is a metabolic disorder resulting from a defect in insulin secretion, insulin action, or both. Insulin deficiency in turn leads to chronic hyperglycaemia with disturbances of carbohydrate, fat, and protein metabolism (1). It is one of the non-communicable diseases which have become a major public health problem with prevalence increasing all over the globe (2) in both urban and rural areas, irrespective of socioeconomic status.

According to recent estimates, approximately 285 million people worldwide (6.6\%) in are with diabetes in 2010 and by 2030, 438 million people $(7.8 \%)$ of the adult population, is expected to have diabetes $(3,4)$.
According to The International Diabetes Federation (IDF) estimation India will have risen in people living with diabetes up to 87.0 million by 2030 from 50.8 million (2010), making it the 'Diabetes Capital' of the world $(3,5,6)$.

DM has been linked with behavioural, environmental, and societal factors such as: ageing populations, increasing urbanization, air pollution, dietary changes, reduced physical activity and unhealthy behaviour, high alcohol intake and high intake of saturated fats. People with diabetes are more prone to have high cholesterol levels, hypertension, obesity leading to cardiovascular diseases (7). As a result, present study was conducted. 


\section{Aims \& Objectives}

1. To determine the prevalence of diabetes.

2. To identify the associated risk factors.

\section{Material \& Methods}

A community based cross sectional study was conducted among individuals residing in all the four blocks (A, B, C, D) of Barrage colony, Rishikesh, Uttarakhand. There are 4 blocks (A, B, C, D) in the Barrage colony of Rishikesh comprising of total 320 Families. During the Tehri Dam construction in Tehri, Uttarakhand the population residing there was shifted by the government to various places in Rishikesh and one of such places is Barrage Colony. As health of migrated population is neglected and such studies have never been conducted in this area so we planned to conduct the study on assessing the morbidity status of this migrated population and the present study is one of the parts of that study. Out of these 320 families 292 families consented to participate in survey. These 292 families comprised of 1193 individuals both male and female and of all age groups. As the prevalence of diabetes is more in the age group more than 20 years so final sample size came out to be 815 . Both male and female more than equal to 20 years of age were surveyed $(8,9)$. Study was conducted for a period of three months starting from January to March 2019.

Inclusion criteria:

1. All individuals (male and female) more than equal to 20 years.

2. All those who gave consent to participate

\section{Exclusion criteria:}

1. Individuals less than 20 years of age

2. Those absent on the day of visit and showing hostile behavior (did not give consent to participate in study).

\section{Data collection}

After explaining the purpose of the study informed consent of participants was taken. Data was collected on predesigned pretested semi structured questionnaire. A house to house survey was done. Information about known diagnosed cases of diabetes and their socio demographic characteristics such as age, gender, type of family, education, occupation, family history of diabetes, history of alcohol consumption was recorded. Waist hip ratio of the participants was measured using flexible non stretchable measuring tape in standing to assess abdominal obesity (WHR $<0.9$ in males and $<0.85$ in females was taken normal). History on regular intake of medication was also taken from participants.

\section{Statistical analysis}

Data was entered into Microsoft Excel and analyzed using epi info software version 7. Pearson's Chi Square test was applied. $P$ value $<0.05$ was considered significant. All the statistical significances were evaluated as $95 \%$ confidence interval level. All the factors found to be statistically significant $(p<0.05)$ on chi square test were evaluated using logistic regression analysis.

\section{Ethical consideration}

Study has been ethically approved by ethical committee of AlIMS Rishikesh

\section{Results}

(Table 1) Shows that out of total 815 participants 413 (50.7\%) were males and 402 (49.3\%) females. Majority of study participants belonged to the age group $20-49$ years 619 (75.9\%), were from nuclear family 594 (72.9\%), were literate619 (75.9\%), had a sedentary work level at occupational arena 435(53.4\%). Also, majority of the respondents had high WHR (abdominal obesity) (51.5\%). $178(21.8 \%)$ had family history of diabetes whereas 141 $(17.3 \%)$ were suffering from hypertension and 131 $(16.7 \%)$ were chronic alcoholic.

(Table 1) Depicts that the overall prevalence of diabetes mellitus was high, $5.6 \%$ among study participants. Although females (6.2\%) were more diabetic than males (5.1\%) but showed no significant association. Statistically significant association was found between diabetes and age factor, type of family, occupation, education, family history of diabetes mellitus, history of hypertension and presence of abdominal obesity.

Univariate simple linear binary logistic regression analysis of correlates of Diabetes mellitus is shown in (Table 2). All the factors found to be statistically significant $(p<0.05)$ on chi square test were evaluated using logistic regression analysis. On univariate analysis all the factors except type of family (nuclear vs joint) were found to be significantly associated with diabetes mellitus. But the odds of age factor (3.5) and family history of diabetes (3.2) was very much high establishing a strong association of these factors with prevalence of Diabetes mellitus.

\section{Discussion}

Our study reflects the correlates of diabetes among 815 adult 20 years of age and above in Rishikesh. In our study overall prevalence of Type 2 DM came out to be $5.6 \%$ which is a little lower than the study done by Sanjeevaiah et al in Hyderabad (6.4\%) (8). Diabetic prevalence was higher in females (6.2\%) than males $(5.1 \%)$ in our study. Similar result was shown by Ahmad et al in Kashmir, females (8.3\%) and males (3.6\%) respectively (9). But Patil et al in Pune (10) showed prevalence of diabetes more in males $(13.7 \%)$, than females $(7.5 \%)$. In the present study the proportion of diabetes mellitus was higher $(11.7 \%)$ in persons aged $\geq 50$ years than in persons aged between 20 and 49 years. Similar result was shown by Sanjeevaiah et al in Hyderabad (17.3\%) (8). Diabetes was also seen more in those consuming alcohol (8.4\%), having history of hypertension (9.9\%) and having family history of diabetes mellitus (11.8\%) and with higher waist-hip ratio (7.4\%). Study done by Tripathy et al (11) showed similar results such as diabetes were seen to be more prevalent among those having family history of Diabetes (11.9\%), history of 
hypertension (14.3\%), those who consumed alcohol (10.4\%) and with higher waist hip ratio (11.7\%). Diabetes was seen to be more prevalent among those from 3 generation families (12.6\%), illiterate (8.2\%), having sedentary occupation (7.3\%). Study done by Bharti et al in Puducherry (12) showed similar results such as diabetes were seen to be more prevalent among illiterate (10.0\%), having sedentary occupation (10.1\%). This shows that maximum diabetic subjects had history of diabetes in their family whether it is either parent or both and had sedentary lifestyle. This shows the importance of family history of diabetes in causing type 2 diabetes mellitus that can act as an alarming signal for those who are not suffering from diabetes currently and also physical activity is required for control and prevention of type 2 diabetes mellitus. In our study the odds of age factor (3.5) and family history of diabetes (3.2) was very much high establishing a strong association of these factors with prevalence of Diabetes mellitus. Similar results were shown by Bharti et al in Puducherry (12) where in logistic regression significant risk factors were: age 50 years and above (OR: 0.247), family history (OR: 2.5) etc.

\section{Conclusion}

The overall prevalence of Diabetes Mellitus found in this study was $5.6 \%$ which is quite high. Prevalence was higher in females, illiterates but not statistically significant. Risk factors like older age, sedentary nature of occupation, family history of diabetes, presence of abdominal obesity, significantly contributed in the occurrence of diabetes. Less than half $(41.3 \%)$ of diabetics took regular medication.

\section{Recommendation}

As diabetes is a SILENT KILLER the level of morbidity and mortality due to diabetes and its complications are enormous posing a significant healthcare burden on both families and society. There is a need to increase awareness of diabetes in the general population. Health education should be given in terms of risk factors of diabetes and people should be made aware about early screening methods. Dietary restrictions and physical activities must be insisted for diabetic patients and aware of the importance of taking food rich in dietary fibers and antioxidants.

\section{Limitation of the study}

Sample size is quite small and the results obtained cannot be generalized to the whole population. As diabetes is a multifactorial disease so due to time constraints many of the factors have not been assessed. No blood sugar estimation has been done due to feasibility issues.

\section{Relevance of the study}

Diabetes mellitus is an emerging global health problem. It is a chronic, noncommunicable, and expensive public health disease. India is the diabetes capital with home to 69.1 million people with DM. As a result, an understanding of the changing epidemiology of diabetes in India is required. Estimation of the prevalence of diabetes and identification of high-risk groups is essential for planning of community-based risk factor reduction interventions.

\section{Authors Contribution}

All authors have contributed equally.

\section{Acknowledgement}

The authors are grateful to the residents of Barrage Colony of Uttarakhand for their cooperation and participation in the study.

\section{References}

1. H. E. Lebovitz, "Diagnosis, classification, and pathogenesis of diabetes mellitus," The Journal of Clinical Psychiatry, vol. 62, Supplement 27, pp. 5-9, 2000.

2. Huizinga MM, Rothman RL. Addressing the diabetes pandemic: $A$ comprehensive approach. Indian J Med Res2006; 124: 481-4.

3. IDF Diabetes Atlas, 4th edition. International Diabetes Federation, 2009.

4. Chan JC, Malik V, Jia W, et al. Diabetes in Asia: Epidemiology, risk factors, and pathophysiology. JAMA 2009; 301:2129-40.

5. Ramachandran A, Wan Ma RC, Snehalatha C. Diabetes in Asia. Lancet 2010; 375:408-18.

6. Diabetes facts

http://www.worlddiabetesfoundation.org/composite35.htm (accessed on 13/1/2012).

7. Menon VU, Guruprasad U, Sundaram KR, Jayakumar RV, Nair V, Kumar H. Glycaemic status and prevalence of comorbid conditions among people with diabetes in Kerala. Natl Med J India. 2008;21(3):112-5Akkiko S, Hosler, Ph.D, Prevalence of selfreported pre-diabetes among adults participating in a communitybased health.

8. Sanjeevaiah A, Sushmitha A, Srikanth T. Prevalence of Diabetes Mellitus and its risk factors. IAIM, 2019; 6(3): 319-324.

9. Ahmad J ,Masoodi M, Ashraf M, Rashid R, Ahmad R, Ahmad A, Dawood S, Prevalence of Diabetes Mellitus and Its Associated Risk Factors in Age Group of 20 Years and Above in Kashmir, India, Al Ameen J Med S ci (2011)4 (1):3 8 -4 4 (An US National Library of Medicine enlisted journal) I S S N0974-1143.

10. Patil R, Gothankar J. Indian Journal of Medical Sciences, JanuaryMarch 2019; Volume 71 (1): 16-21.

11. Tripathy J.P, Thakur J.S, Jeet G, Chawla S, Jain S, Pal A, Prasad R, Saran R, Prevalence and risk factors of diabetes in a large community-based study in North India: results from a STEPS survey in Punjab, India, Diabetol Metab Syndr (2017) 9:8: 1-8.

12. Bharti D R, Pal R,Kar S, R. Rekha, T. V. Yamuna, BasuM, Prevalence and determinants of diabetes mellitus in Puducherry, South India, Journal of Pharmacy and Bioallied Science. 2011 Oct-Dec; 3(4): 513-518. 
Tables

TABLE 1 ASSOCIATION OF DIABETES MELLITUS WITH SOCIODEMOGRAPHIC AND BEHAVIORAL FACTORS OF STUDY PARTICIPANTS ( $\mathrm{N}=815)$.

\begin{tabular}{|c|c|c|c|c|}
\hline \multirow[t]{2}{*}{ Variables } & \multirow{2}{*}{$\begin{array}{l}\text { Frequency } \\
\mathrm{N}(\%)\end{array}$} & \multicolumn{2}{|l|}{ Diabetes } & \multirow[t]{2}{*}{ Chi Square $p$ Value } \\
\hline & & Yes N (\%) & No N (\%) & \\
\hline \multicolumn{4}{|c|}{ Age group (in years) } & \multirow{3}{*}{$\begin{array}{c}X 2: 21.1 \\
\text { p value: }<0.05\end{array}$} \\
\hline $20-49$ & $619(75.9 \%)$ & $22(3.5 \%)$ & $597(96.5 \%)$ & \\
\hline$\geq 50$ years & $196(24.1 \%)$ & $24(12.2 \%)$ & $172(87.8 \%)$ & \\
\hline \multicolumn{4}{|l|}{ Gender } & \multirow{3}{*}{$\begin{array}{c}X 2: 0.492 \\
p \text { value: }>0.05\end{array}$} \\
\hline Male & $413(50.7 \%)$ & $21(5.1 \%)$ & $392(94.9 \%)$ & \\
\hline Female & $402(49.3 \%)$ & $25(6.2 \%)$ & 377 (93.8\%) & \\
\hline \multicolumn{4}{|l|}{ Type of Family } & \multirow{3}{*}{$\begin{array}{c}\mathrm{X} 2: 4.965 \\
\mathrm{p} \text { value: }<0.05\end{array}$} \\
\hline Nuclear & $594(72.9 \%)$ & $27(4.5 \%)$ & $567(95.5 \%)$ & \\
\hline Joint & $221(27.1 \%)$ & $19(8.6 \%)$ & $202(91.4 \%)$ & \\
\hline \multicolumn{4}{|l|}{ Education } & \multirow{3}{*}{$\begin{array}{c}X 2: 4.447 \\
p \text { value: }<0.05\end{array}$} \\
\hline Literate & $619(75.9 \%)$ & $29(4.6 \%)$ & $590(95.3 \%)$ & \\
\hline Illiterate & $196(24.1 \%)$ & $17(8.7 \%)$ & $179(91.3 \%)$ & \\
\hline \multicolumn{4}{|l|}{ Occupation } & \multirow{3}{*}{$\begin{array}{r}\mathrm{X} 2: 10.106 \\
\mathrm{p} \text { value: }<0.05\end{array}$} \\
\hline Non-Sedentary & $380(53.4 \%)$ & $11(2.9 \%)$ & $369(97.1 \%)$ & \\
\hline Sedentary & $435(53.4 \%)$ & $35(8.0 \%)$ & $400(92.0 \%)$ & \\
\hline \multicolumn{4}{|c|}{ Family History of Diabetes } & \multirow{3}{*}{$\begin{array}{c}\mathrm{X} 2: 16.193 \\
\text { p value: }<0.05\end{array}$} \\
\hline Yes & $178(21.8 \%)$ & $21(11.8 \%)$ & $157(88.2 \%)$ & \\
\hline No & $637(78.2 \%)$ & $25(3.9 \%)$ & $612(96.1 \%)$ & \\
\hline \multicolumn{4}{|c|}{ Abdominal Obesity } & \multirow{3}{*}{$\begin{array}{c}X 2: 4.908 \\
\text { p value: }<0.05\end{array}$} \\
\hline Yes & $420(51.5 \%)$ & $31(7.4 \%)$ & $389(92.6 \%)$ & \\
\hline No & 395 (48.5\%) & $15(3.8 \%)$ & $380(96.2 \%)$ & \\
\hline \multicolumn{4}{|c|}{ History of hypertension } & \multirow{3}{*}{$\begin{array}{c}X 2: 5.878 \\
\text { p value: }<0.05\end{array}$} \\
\hline Yes & $141(17.3 \%)$ & $14(9.9 \%)$ & $127(90.1 \%)$ & \\
\hline No & $674(82.7)$ & $32(4.7 \%)$ & $642(95.3 \%)$ & \\
\hline \multicolumn{4}{|c|}{ Consumption of alcohol } & \multirow{3}{*}{$\begin{array}{c}X 2: 2.221 \\
\text { p value: }>0.05\end{array}$} \\
\hline Yes & $131(16.1 \%)$ & $11(8.4 \%)$ & $120(91.6 \%)$ & \\
\hline No & $684(83.9 \%)$ & $35(5.1 \%)$ & $649(94.9 \%)$ & \\
\hline
\end{tabular}

TABLE 2 CORRELATES OF DIABETES MELLITUS: LOGISTIC REGRESSION ANALYSIS ( $\mathbf{N = 8 1 5}$ )

\begin{tabular}{|c|c|c|c|c|}
\hline \multicolumn{2}{|l|}{ Socio demographic factors } & \multirow{3}{*}{$\begin{array}{l}\text { ODD's Ratio } \\
3.5076\end{array}$} & \multirow{3}{*}{$\begin{array}{l}95 \% \mathrm{Cl} \\
1.8578\end{array}$} & \multirow{3}{*}{$\begin{array}{l}\text { P Value } \\
<0.05\end{array}$} \\
\hline Age Groups (in years) & 20- 49 & & & \\
\hline & $\geq 50$ years & & & \\
\hline \multirow[t]{2}{*}{ Type of Family } & Nuclear & \multirow[t]{2}{*}{1.9537} & \multirow[t]{2}{*}{0.9981} & \multirow[t]{2}{*}{$>0.05$} \\
\hline & Joint & & & \\
\hline \multirow[t]{2}{*}{ Education } & Literate & \multirow[t]{2}{*}{2.5930} & \multirow[t]{2}{*}{1.2562} & \multirow[t]{2}{*}{$<0.05$} \\
\hline & Illiterate & & & \\
\hline \multirow[t]{2}{*}{ Occupation } & Non-Sedentary & \multirow[t]{2}{*}{2.2684} & \multirow[t]{2}{*}{1.0784} & \multirow[t]{2}{*}{$<0.05$} \\
\hline & Sedentary & & & \\
\hline \multirow[t]{2}{*}{ Family History of Diabetes } & Yes & \multirow[t]{2}{*}{3.1527} & \multirow[t]{2}{*}{1.6195} & \multirow[t]{2}{*}{$<0.05$} \\
\hline & No & & & \\
\hline \multirow[t]{2}{*}{ Abdominal Obesity } & Yes & \multirow[t]{2}{*}{2.7667} & \multirow[t]{2}{*}{1.3549} & \multirow[t]{2}{*}{$<0.05$} \\
\hline & No & & & \\
\hline History of hypertension & Yes & 2.3423 & 1.0918 & $<0.05$ \\
\hline
\end{tabular}

